\title{
Sou cego ou enxergo? \\ As questões da baixa visão
}

\section{Am I blind or seeing? The questions of low vision}

\author{
Maria Lúcia Toledo Moraes Amiralian*
}

\begin{abstract}
RESUMO
Este texto propõe-se a discutir as dificuldades afetivo-emocionais das pessoas com baixa visão. A partir da década de 70, especialistas começaram a se preocupar com o uso efetivo da visão residual. Contudo, esses estudos se desenvolveram principalmente na área médica, educacional e tecnológica. Pesquisas na área da psicologia, em sua maioria, ainda estão centralizadas nos efeitos psicológicos da cegueira. Parece haver uma crença de que as descobertas obtidas por meio de pesquisas realizadas com pessoas cegas são esclarecedoras sobre as questões cognitivas e afetivo-emocionais das pessoas com baixa visão. Todavia, estudo realizado mostrou dificuldades específicas a esse grupo de pessoas. Duas questões básicas foram observadas e analisadas: a questão da identidade pessoal e a questão da pertença. Foram propostos temas a serem abordados por futuros estudos.

Palavras-chave: deficiência visual, baixa visão, identidade pessoal, pertença.
\end{abstract}

\begin{abstract}
This text intends to discuss the emotional disturbs of people with low vision. In the seventies, specialists started to study the effective use of residual vision. But studies about this issue were centralized in the medical,

${ }^{*}$ Doutora em Psicologia Clínica pela Universidade de São Paulo-USP. Professora no Instituto de Psicologia da Universidade de São Paulo, no Programa de Pós-Graduação em Psicologia Escolar e do Desenvolvimento Humano. Coordenadora do LIDE - Laboratório Interunidades para o Estudo das Deficiências, na Universidade de São Paulo. E-mail: mltma@usp.br
\end{abstract}


pedagogical and technological areas. Researches in the psychological area are, mostly, still centralized in the psychological effects of blindness. They share the opinion that the discoveries about blind people can be applied to low vision people, but studies with those people have shown peculiar problems to this group. Two basic problems were observed and analyzed: the identity issues and the appurtenance issues. Topics were proposed for future researches.

Key-words: visual impairment, low vision, personal identity, appurtenance.

Embora as classificações sobre os deficientes visuais incluam já há muito tempo dois grupos bem distintos de pessoas - os cegos e aqueles com baixa visão -, só a partir da década de 70 , aqui no Brasil ${ }^{1}$, é que se observa uma preocupação dos especialistas com a questão da visão subnormal.

Até esse momento, a identificação dos deficientes visuais baseava-se no diagnóstico oftalmológico e consistia na acuidade visual medida pelos oftalmologistas. Eram considerados cegos aqueles que apresentavam acuidade visual entre 0 e 20/200 pés no melhor olho após correção máxima, ou que tinham um ângulo visual restrito a $20^{\circ}$ de amplitude, definição de "cegueira legal" elaborada pela Associação Médica Americana em 1934 e que era utilizada para encaminhamento dos alunos para o ensino do Braille.

Entretanto, a constatação de que muitas crianças "cegas" liam o Braille com os olhos levou os especialistas a uma reformulação, propondo um diagnóstico educacional de deficiência visual que dava ênfase à maneira como o indivíduo é capaz de utilizar a percepção visual em seu processo de aprendizagem (AMIRALIAN, 1997), surgindo a preocupação com o uso do resíduo visual.

Um aspecto interessante que se pode observar são as mudanças que ocorreram na nomeação dada às pessoas com baixa visão. LOWENFELD (1950) classificava os deficientes visuais como cegos, parcialmente videntes e parcialmente cegos, termo utilizado por muitos autores - TELFORD e SAWREY (1976), KIRK (1972), Samuel ASHCROFT (1971) -, revelando que a preocupação básica naquele momento era com o problema da cegueira e suas conseqüências. Este fato pode ser comprovado pelos estudos e pesquisas na área, tanto sobre questões de ensino-aprendizagem como sobre os aspectos afetivo-emocionais, centrados nas questões da ausência de visão.

\footnotetext{
${ }^{1}$ Nos Estados Unidos, essa preocupação surgiu em 1964 com Barraga.
} 
Estudos e trabalhos científicos sobre as questões da deficiência visual no campo da psicologia até a década de 70, e mesmo até os dias atuais, referem-se, preferencialmente, às pessoas cegas e com cegueira congênita. Há inúmeros trabalhos sobre o desenvolvimento cognitivo na ausência da visão; estudos sobre a imagem mental dos cegos, a formação de conceitos, a organização e estruturação do espaço, além daqueles sobre os aspectos afetivos e emocionais, desenvolvimento e ajustamento da personalidade. Considera-se que a grande questão é o ver ou o não ver, e que a compreensão das dificuldades do cego e dos efeitos causados pela cegueira ao desenvolvimento e ajustamento das pessoas, nas mais variadas situações, inclui as questões e os problemas pertinentes às pessoas com baixa visão. Parte-se do princípio de que eles são os mesmos, apenas em menor grau.

Aliado a esse fator há o pouco conhecimento sobre o uso e a eficácia do desenvolvimento do resíduo visual e a pouca importância dada a ele como uma condição que facilita e melhora a qualidade de vida das pessoas que o possuem.

Outra explicação possível para esse fato talvez tenha sido a valorização, naquele momento, das pesquisas quantitativas baseadas no modelo das ciências naturais, com o propósito de asseverar a condição da psicologia como ciência. A pesquisa com cegos congênitos constituía-se de uma variável mais facilmente controlada. A baixa visão e a cegueira adquirida são variáveis de difícil controle, pela diversidade de fenômenos a elas relacionados: diferentes graus de acuidade e de eficiência visual e diferentes idades da perda visual. Esses são fatores complicadores quando se é necessário definir e quantificar o objeto da pesquisa. Em pesquisas da década de 60 são encontrados relatos em que os indivíduos com visão residual eram vendados, para impedir o que se considerava uma distorção da amostra.

Na década de 70 passou-se a utilizar, no Brasil, o termo "visão reduzida", mudando-se o eixo da cegueira para a visão, quando os especialistas começaram a se preocupar, cada vez mais, com o uso efetivo de qualquer resíduo visual existente. Embora tivesse havido mudança de foco - não era mais o parcialmente cego mas o indivíduo com visão reduzida -, pode-se dizer que esta terminologia ainda contém uma centralização na perda da visão e não na capacidade visual.

Com o passar do tempo, essa impropriedade do termo começou a incomodar alguns especialistas. Argumentavam que na realidade não havia uma visão reduzida, mas um indivíduo que por problemas orgânicos possuía uma capacidade limitada para perceber visualmente o mundo ao seu redor. A partir daí o nome que, no Brasil, passou-se a usar foi "visão subnormal", uma tradução do termo "low vision" usado por BARRAGA (1964). Esse termo é, até 
o momento, bastante usado, inclusive em documentos oficiais. Observa-se, todavia, que também essa terminologia está em processo de transformação. Os especialistas têm agora procurado utilizar o termo "baixa visão", acreditando que esse tende a minimizar o preconceito que o termo "subnormal" pode provocar.

A questão da baixa visão passou então a se constituir como primordial, principalmente para os oftalmologistas e educadores.

Há muitas razões que justificam essa preocupação. Dentre elas podemse apontar algumas consideradas básicas:

- $\quad$ Entre as pessoas com deficiência visual, de $70 \%$ a $80 \%$ possui alguma visão útil.

- $\quad$ A não utilização efetiva do resíduo visual, por menor que ele seja, leva a uma diminuição da eficiência visual.

- O uso de qualquer resíduo visual poderá ajudar as pessoas com baixa visão na realização de inúmeras tarefas, tais como:

- Constituição e organização do espaço - uma das grandes dificuldades enfrentadas por aqueles que não enxergam é construir a noção de espaço e sua relação com ele, e qualquer resíduo visual possibilita à criança perceber com maior facilidade onde ela está, onde estão os objetos e a relação entre eles.

- Na coordenação dos movimentos.

- Na mobilidade e locomoção.

- No contato e relação com o ambiente - para a criança com baixa visão, seja qual for a percepção visual, fica mais fácil identificar prontamente as dimensões e características gerais de um ambiente e verificar a presença ou ausência de alguém.

- Na aprendizagem por imitação - uma das importantes formas de aprendizagem é a imitação, e muito do que somos e sabemos nos vem pela imitação visual. A criança cega precisa substituir esse canal de aprendizagem, mas nos casos em que há baixa visão, a informação visual, por menor que seja, pode servir de ajuda na aprendizagem da criança.

- $\mathrm{Na}$ aprendizagem da leitura e da escrita - saber ler e escrever a linguagem comum é de grande importância, possibilita aos indivíduos ficar a par das últimas novidades e das informações mais recentes veiculadas pelos meios impressos de comunicação.

Por essas razões, a preocupação maior com essa questão centrou-se na busca do melhor uso da visão que o indivíduo possui, obtida tanto por meio de desenvolvimento de recursos ópticos, tecnológicos e educacionais para melhorar a capacidade visual, como pelo incentivo para o treinamento dessa visão. 
Muitos estudos e pesquisas têm se desenvolvido sobre esse tema, principalmente nas áreas médica e educacional. A partir de 1980, são encontrados muitos trabalhos acadêmicos com questões referentes ao melhor uso do resíduo visual e sobre a educação das crianças com baixa visão. Pode-se dizer que houve, por parte dos especialistas, uma tentativa de mudança do foco da cegueira para o da possibilidade de ver.

Todavia, verifica-se que o desenvolvimento de trabalhos e pesquisas ficou centrado nas áreas do conhecimento médico, pedagógico e tecnológico. Estudos e pesquisas sobre os efeitos dessa condição no desenvolvimento psíquico do ser humano, ou sobre as dificuldades afetivo-emocionais que atingem aqueles que se vêem limitados no uso da visão, é um assunto ainda muito pouco explorado. Parece ainda permanecer a crença de que as dificuldades emocionais vividas pelos indivíduos com baixa visão são as mesmas dos cegos, apenas minimizadas.

Em pesquisa realizada no LIDE - "A criança deficiente visual com problemas de aprendizagem: um modelo para atendimento integral" (AMIRALIAN et al., 2002) $)^{2}$, que se propôs a identificar alunos de escolas regulares com deficiência visual que apresentavam problemas de aprendizagem, com o objetivo de propor um modelo para seu atendimento, teve entre seus sujeitos casos de alunos com baixa visão. Sendo uma pesquisa qualitativa, permitiu a análise de fenômenos que ocorrem especificamente com esse grupo. Observou-se que essa limitação interfere no desenvolvimento e organização da personalidade de forma peculiar. Pode-se verificar a inadequação da simples transposição dos conhecimentos adquiridos sobre as pessoas cegas para elas. Foram constatadas características peculiares e problemas próprios às pessoas com baixa visão.

\section{Problemas específicos às pessoas com baixa visão}

Podem-se observar dois problemas que afetam diretamente essas pessoas, trazendo complicações para sua educação e para a organização de sua personalidade: falta de identificação desses alunos como pessoas com baixa visão e o deslocamento da sua problemática para outras áreas.

\footnotetext{
${ }^{2}$ Trabalho realizado com o apoio do CNPq e Capes.
} 
Em relação à questão da falta de identificação do aluno como possuidor de baixa visão, um aspecto notado foi que quase nunca eles são tratados como pessoas que possuem capacidade limitada para perceber visualmente o mundo ao seu redor. São tratadas às vezes como pessoas cegas e em outros momentos como pessoas visualmente normais. Parece não existir uma compreensão clara e definida do que sejam pessoas com baixa visão.

A ausência de identificação das crianças com visão subnormal já foi demonstrada por pesquisas (GARCIA, 1984) em que se verificou que as crianças que freqüentavam as salas de recursos para deficientes visuais eram predominantemente educadas pelos professores especializados, e consideradas pela comunidade escolar como crianças cegas, embora a maioria delas possuísse resíduo visual.

Embora se verifique que os estudiosos definam com clareza esse subgrupo da deficiência visual, um fenômeno observado é como isto é pouco assimilado pela comunidade de um modo geral. Tanto os professores, alunos e comunidade escolar, como os pais e todas as pessoas com quem esses alunos convivem, parecem só conhecer duas possibilidades de ser: ser cego ou ser daqueles que enxergam. Por essa razão, suas dificuldades de aprendizagem ou afetivo-emocionais raramente são relacionadas à condição de dificuldades de percepção visual, mas tratadas como outros problemas.

A atitude dos pais e dos profissionais também oscilava entre dois extremos: ora tratavam esses jovens como cegos, ora como pessoas que enxergam. Os pais não permitiam que eles fossem sós para escola, embora adolescentes, e pediam sempre que os irmãos menores os acompanhassem. Por outro lado, esses pais não mostravam preocupação em lhes proporcionar recursos pedagógicos especiais necessários para sua aprendizagem, como recursos ópticos, cadernos com pautas largas e lápis com ponta grossa.

A ausência de clareza sobre como essas crianças percebem o mundo os levavam a considerar as dificuldades da criança como decorrentes de outras incapacidades pessoais, e não de sua limitação para enxergar. As dificuldades de realização, tanto as que se referiam às tarefas escolares como a comportamentos sociais eram, na maioria das vezes, computadas à ineficiência, à incapacidade mental ou à falta de vontade. Entre os casos atendidos, verificou-se um aluno que era identificado pela mãe como incapaz de aprender, e pelos professores como tendo limitação intelectual. Nas atividades da pesquisa por ele realizadas, podem-se observar rápidos progressos na aprendizagem e tipos de raciocínio que descartavam a condição de deficiência mental, revelando a inconsistência desses apressados "diagnósticos" feitos muitas vezes por pais e professores. Para outro aluno, era imputada uma condição de total desin- 
teresse para a aprendizagem. Achavam que havia, de sua parte, falta de esforço pessoal. De nossa parte, foram constatadas muitas dificuldades afetivoemocionais relacionadas a ansiedades causadas pela não satisfação de suas necessidades como pessoa com baixa visão.

Essas dificuldades provocavam nos pais, por um lado, uma atitude de conformismo - meu filho não aprende mesmo - levando-os a se desinteressar pelas atividades escolares de seus filhos e pela providência dos recursos básicos para a sua aprendizagem, e por outro lado uma atitude de exigência excessiva para com o treinamento do resíduo visual, chegando mesmo, algumas vezes, a tentar impedi-los ou a desencorajá-los a usar seus outros sentidos para uma ajuda na percepção de mundo externo, numa tentativa de transformálos em pessoas totalmente videntes.

A observação desses fenômenos permitiu o levantamento de algumas hipóteses:

- Há uma absoluta falta de compreensão da população em geral do que seja a visão subnormal.

- Há uma falta de compreensão das vicissitudes afetivo-emocionais a que estão expostas as pessoas que sofrem dessa condição.

Especialistas (CARVALHO et al., 1994) consideram a baixa visão uma perda grave que não pode ser corrigida por tratamento clínico ou cirúrgico, nem com lentes convencionais. Uma definição abrangente considera uma pessoa com baixa visão: "aquela que possui um comprometimento do seu funcionamento visual, mesmo após tratamento clínico e/ou correção óptica, e apresenta uma acuidade visual, no melhor olho, entre 6/18 à percepção luminosa, ou campo visual inferior a 10 graus do seu ponto de fixação, e que usa ou é potencialmente capaz de utilizar a visão para planejar e/ou executar uma tarefa." (GASPARETTO, 2001).

A baixa visão é considerada uma dificuldade visual de graus variáveis, que causa incapacidade funcional e diminuição do desempenho visual. Segundo esses especialistas, esta incapacidade não está relacionada apenas aos fatores visuais, mas é influenciada pela reação das pessoas à perda visual, e aos fatores ambientais que interferem em seu desempenho.

Esses conceitos, embora clinicamente claros e concisos, não informam como a criança vê o mundo. Falam sobre os limites do que considerar como visão subnormal, mas não conduzem a uma compreensão clara de como a criança enxerga, ou seja, de que maneira as pessoas com baixa visão apreendem o mundo externo e de que maneira essas pessoas organizam ou reorganizam a sua percepção. A falta de clareza sobre o que realmente significa enxergar menos leva a uma fragilidade do conceito que identifica o que é e como se constitui a pessoa com baixa visão. 
Sabe-se o que é enxergar ou não enxergar, mas é muito difícil compreender limitações que variam não só em relação à acuidade visual, mas, também, em relação ao campo visual, à sensibilidade aos contrastes, à adaptação à luz e ao escuro, à percepção de cores e principalmente, à eficácia no uso da visão.

A ausência de identificação das crianças que possuem baixa visão constitui-se como um problema nuclear, o que já foi demonstrado por diferentes pesquisas acima citadas.

Aliada a essa problemática observou-se, no estudo realizado no LIDE (AMIRALIAN et al., 2002), que esses alunos não tinham clareza a respeito de suas possibilidades e limitações visuais: eles não sabiam o que é enxergar bem, nem a diferença entre sua maneira de enxergar e a da maioria das pessoas. De forma semelhante, seus pais e professores não tinham conhecimento de como eles enxergavam e quais as implicações que isso poderia trazer ao seu desenvolvimento e aprendizagem.

Essa definição médica de baixa visão fala dos limites da acuidade visual considerada visão subnormal mas, por dificuldades inerentes à própria condição, torna-se indefinida em suas características, o que contribui para dificultar pesquisas com esse grupo de pessoas, embora ele se constitua como o maior dentre os deficientes visuais.

A situação verificada a partir do atendimento de alunos com baixa visão que apresentavam problemas de aprendizagem, que emergiu da pesquisa realizada, permitiu a observação de algumas dificuldades básicas que são cotidianamente vivenciadas por essas crianças e jovens: a questão da identidade e a questão da pertença. Questões que, acredita-se, possam constituir um ponto de partida para uma maior compreensão das dificuldades vividas por essas pessoas.

\section{A questão da identidade}

A identidade pessoal é a condição básica para o desenvolvimento psíquico do ser humano. A constituição dessa identidade e seu fortalecimento e definição, conquistados durante o percurso do desenvolvimento, são a base sobre a qual se constrói a personalidade individual.

Saber "quem sou Eu" é um sentimento fundamental do ser humano, ele nos diz o que somos e como somos. Segundo winNicotT (1975), é uma con- 
seqüência da tendência inata a continuar a existir e constitui-se pela identificação da mãe com seu bebê, que possibilita a identificação primária deste para com a mãe.

Para esse autor, no estágio inicial de desenvolvimento, a interação com o ambiente (a mãe) é considerada primordial, sendo as qualidades dessa interação, e os cuidados fornecidos, elementos essenciais. Nessa fase a relação mãe-bebê é paradoxal: é a coexistência de dois em um, mãe e bebê como seres indiferenciados, “... no sentido de o bebê tornar-se o seio (ou a mãe), no sentido de que o objeto é o sujeito...” (winNicotT, 1975, p. 113). Essa condição é o que, para winNICOTT, torna possível a constituição da identidade pessoal.

Continuando seu pensamento, diz: “...e a experiência a esse respeito abre caminho para o sujeito que se objetivou, isto é, a idéia de um si mesmo (self) e o sentimento do real que se origina do sentimento de possuir uma identidade" (winNicotT, 1975, p. 114). E é a partir dessa condição que o ser humano torna-se capaz de viver experiências que podem ser sentidas como próprias.

A definição da identidade pessoal vai se fortalecendo e se enriquecendo no seio das relações interpessoais pelo espelho que o olhar do outro oferece, pela confiança no ambiente que realimenta a si mesmo e pela reafirmação das competências pessoais que fortalecem o ego.

WINNICOTT (1975) já falava sobre o papel de espelho que o olhar da mãe tem sobre o bebê e como esse traz a marca da identidade pessoal, "o que vê o bebê quando olha para o rosto da mãe? Sugiro que, normalmente, o que o bebê vê é ele mesmo. Em outros termos, a mãe está olhando para o bebê e aquilo com que ela se parece se acha relacionado com o que ela vê ali” (p. 154).

Após esse início, que constitui a base de todo o desenvolvimento posterior no qual vão se assentar as experiências vividas por todos em seu caminho de desenvolvimento, torna-se fundamental o tipo de relações interpessoais vividas por cada um em suas experiências de vida.

É importante para todas as crianças a forma de relacionamento que ocorre com seus pais, irmãos, tios, avós, vizinhos, colegas, professores, enfim, com todos ao seu redor. Se nessas interações houver elementos facilitadores para se confirmar a confiança no ambiente e, principalmente, a crença de que o outro não é um inimigo a ser temido, mas um amigo que trará prazeres e satisfações, haverá a confiabilidade no ambiente e a possibilidade de o indivíduo expressar-se espontaneamente, ser ele mesmo e fortificar sua identidade pessoal.

Além disso, uma condição que reforça o ego é a reafirmação das competências pessoais. Se minhas ações forem aprovadas, se meu jeito de ser for 
valorizado, se minhas conquistas forem percebidas e minhas dificuldades compreendidas, eu sei quem eu sou, sou capaz de entender meus limites, ou seja, sou capaz de discriminar as minhas capacidades e as minhas impossibilidades.

Pode-se constatar, todavia, que a baixa visão traz dificuldades para a construção e definição da identidade pessoal desde o seu início por duas razões: pela dificuldade da mãe de identificar-se com seu bebê diferente e pelas dificuldades que são vivenciadas nas relações interpessoais entre os que enxergam e aqueles que possuem baixa visão em diferentes situações durante toda sua vida.

Podem-se compreender as dificuldades de uma mãe para se identificar com seu bebê com deficiência visual, tanto nos casos em que ela tem conhecimento da problemática visual de seu filho como naqueles casos em que há total desconhecimento do fato.

Supondo que para a mãe haja, desde o início, clareza sobre o diagnóstico visual de seu filho e o entendimento de que ele terá sempre uma limitação visual não corrigível, ao olhar para esse bebê ela o verá como um bebê diferente e se perguntará: como ele enxerga?, como ele vai me reconhecer?, como eu vou saber o que ele quer? Além disso, a situação traumática vivida por essa mãe com a notícia da limitação visual de seu bebê pode conduzi-la a sentimentos depressivos e de angústia de graus variados, o que levará o bebê a reagir diante dessa intrusão ambiental (wINNICOTT, 1990), tornando-se submisso, não expressando seu verdadeiro "self" e não construindo condições para assumir e expressar seu verdadeiro si mesmo.

Nos casos em que a mãe não tem conhecimento sobre o diagnóstico, a incerteza poderá ser maior diante das respostas incomuns do bebê: o que meu filho tem?, será que ele vai se desenvolver?, qual a doença que ele tem?, o que fiz de errado?, como agir com ele? E essa situação confusa e indefinida poderá parecer caótica para a criança, não permitindo que ela crie sentimentos de confiabilidade para com o ambiente, causando-lhe grande insegurança, dificuldade em expressar-se e em sentir prazer e interesse para buscar contato com o mundo externo.

No decorrer do desenvolvimento, as crianças e os jovens vão definindo e firmando sua identidade pelas experiências ocorridas nas relações interpessoais. Mas, para as pessoas com baixa visão, o ambiente, tanto o social quanto o físico, continuará confuso.

Como as crianças com baixa visão ou são consideradas e tratadas como crianças cegas ou tratadas e consideradas como crianças videntes, elas não têm um espelho que reflita aquilo que elas realmente são. Considerando as 
relações interpessoais, vê-se que o olhar do outro, em quase todas as situações, desde as familiares até as relações profissionais e sociais, freqüentemente irão refletir ambigüidade: será que ele está enxergando?, ou não?, como devo me relacionar com uma pessoa com baixa visão?, ele deve ser tratado como cego ou como uma pessoa que enxerga?

Esse espelho distorcido concorre para uma identidade pessoal indefinida, reafirmando sua insegurança: quem sou eu?, sou cego?, mas eu enxergo sou vidente?, mas por que outros são capazes de perceber coisas que eu não percebo? Essa incerteza sobre si mesma leva a criança, com freqüência, a desenvolver uma auto-imagem negativa, dependência do ambiente e alto nível de ansiedade.

Por outro lado, o fato de as pessoas de um modo geral não saberem como se relacionar com os indivíduos com baixa visão ocasiona outra circunstância também prejudicial a eles: suas necessidades nem sempre são satisfeitas, um elemento a mais colaborando para dificuldades em sua identidade pessoal. O fato central que deveria ser compreendido por todos é que, na realidade, elas não são nem cegas nem videntes, são crianças que precisam construir uma identidade como pessoas com baixa visão.

Além desses, outros aspectos podem estar relacionados a dificuldades na construção da identidade pessoal. As dificuldades nas interações podem provocar a ocorrência de falhas no processo de integração e personalização de seu próprio corpo e de suas funções (wINNICOTT, 1990), conduzindo a criança a dificuldades em assumir-se e expressar-se de forma espontânea.

Os alunos com baixa visão sujeitos da pesquisa realizada mostraram-se muito passivos, submissos ao ambiente, com pouco espaço para expor-se e vivenciar efetivamente as experiências escolares. Essas dificuldades pareciam constituir uma das causas de seus problemas de aprendizagem. A percepção de si mesmo, construída sobre suas realizações, apoiava-se em uma certeza de fracasso que muitas vezes se confirmava. Esse círculo vicioso de baixa expectativa pessoal seguida de baixa realização confirmava sua auto- imagem negativa e os impedia de buscar novas formas de realização.

Além desses aspectos deve-se considerar também a inconsistência do ambiente físico. A inconstância na utilização eficiente do resíduo é uma condição inerente à baixa visão. A percepção visual do ambiente físico é extremamente variável, seja por diferenças de iluminação, de distância do objeto, por mudança na posição da cabeça e direção do olhar para a percepção visual do ambiente ou por condições afetivas e emocionais que interferem na eficiência visual. Essas são outras condições que colaboram para que esses indivíduos venham a ter pouca confiança no ambiente. 


\section{A questão da pertença}

O ser humano é um ser social por natureza, ele só se constitui na presença de outro ser humano, e só se desenvolve pela interação com os outros e, como um indivíduo essencialmente social, tem necessidade de sentir-se como pertencente a um grupo.

Esse sentimento de pertencimento nos leva a discriminar aqueles que são nossos iguais daqueles que não são os nossos iguais. Em todos os ambientes - escolares, profissionais e sociais -, vemos a organização de grupos que se identificam em razão de diferentes condições.

Mas um fato observado é que as crianças e jovens com baixa visão estão, com freqüência, isolados. Algumas vezes identificam-se com os cegos, outras com os videntes, mas nas duas situações sentem-se como se estivessem de fora, não estão em casa, esse não é o seu grupo.

O sentimento de igualdade e pertencimento é um local de descanso para o ser humano. Precisamos saber qual é nossa família, nosso clube, nosso país, nossos colegas, enfim, nossos iguais. O sentimento de pertença nos permite identificar qual é o nosso grupo e saber quem são aqueles que podem compreender as nossas dificuldades e alegrias.

Um aspecto importante a ser salientado é que a condição visual não deveria se constituir como fator preponderante na construção de identidade de qualquer pessoa. Todos são constituídos por um conjunto de características que se manifestam e expressam quem é aquela pessoa, qual é sua personalidade, o que a faz ser aquilo que ela é. São características psicossomáticas do indivíduo, construídas na interação com o ambiente. São as características orgânicas e fisiológicas, psíquicas e mentais do indivíduo, construídas pelas interações ocorridas em determinada família, cultura, condição socioeconômica, enfim todo um conjunto de diferentes aspectos que formam o EU, que nos faz ser o que somos e nos leva a nos aproximarmos de um grupo ou outro. Mas, para as pessoas com baixa visão, ou mesmo para todas aquelas com qualquer outra limitação física ou funcional, a condição de deficiência passa a ser a única pela qual a pessoa passa a ser reconhecida e da qual se apropria.

A ausência de um grupo definido de visão subnormal concorre para a dificuldade desses indivíduos em se aliarem com outros para a formação de um grupo, levando-os mais uma vez à desconfiança no ambiente, ao isolamento e bloqueio na comunicação, sentimentos observados nos alunos atendidos pela referida pesquisa. 
Creio poder afirmar que este trabalho trouxe algumas certezas, mas muitas dúvidas. Temos certeza que às pessoas com baixa visão não podem ser computadas as mesmas descobertas feitas em estudos com cegos. Elas não têm os mesmos problemas, em menor grau. Por outro lado, este trabalho mostrou o extenso campo de pesquisa a ser percorrido para que se possa melhor compreender e atender as pessoas com baixa visão.

Concluindo, fica-nos a certeza de que uma possível minimização desses problemas pode vir a ocorrer se os profissionais se dedicarem a pesquisas que levem a um conjunto de informações que torne possível a construção de conceitos que indiquem as condições específicas que caracterizam as pessoas com baixa visão. São importantes estudos que tragam luzes sobre as características perceptivas peculiares às pessoas com baixa visão, sobre os riscos que essas pessoas correm em seu processo de desenvolvimento e na organização de seu eu e sobre a que formas e tipos de dificuldades essas pessoas estão expostas em suas relações interpessoais.

\section{REFERÊNCIAS}

AMIRALIAN, M. L. T. M. Compreendendo o cego. Uma visão psicanalítica da cegueira por meio de desenhos-estórias. São Paulo: Casa do Psicólogo, Fapesp, 1997.

et al. A criança deficiente visual com problemas de aprendizagem: um modelo para atendimento integral, Pesquisa realizada no Lide/ IPUSP com apoio do CNPq e Capes. São Paulo, 2002.

ASHCROFT, S. C. Crianças cegas e amblíopes. In: DUNN, L. M. Crianças excepcionais - seus problemas, sua educação. Rio de Janeiro: Ao Livro Técnico, 1971, p. 309-345.

BARRAGA, N. C. Increased visual behavior in low vision children. New York: American Foundation for the Blind, 1964.

CARVALHO, K. M. M. et al. Visão subnormal: Orientações ao professor do ensino regular. Campinas: Unicamp, 1994, 48 p.

GARCIA, N. Da necessidade de programas de treinamento de visão subnormal em Crianças. São Paulo, 1984. Dissertação (Mestrado em Educação) - PUC-SP.

GASPARETTO, M. E. R. F. A baixa visão e o sistema braille. In: SIMPÓSIO SOBRE O SISTEMA BRAILLE, 1., Anais... Salvador: BH, SEESP/MEC, 2001. p. 37-41. 
LOWENFELD, B. Psychological Foundation of Special Methods in Teaching Blind Children. In: ZAHL, P. A. Blindness. New Jersey: Princeton University Press, 1950, p. 89-108.

TELFORD, C. W.; SAWREY, J. M. O indivíduo excepcional. Rio de Janeiro: Zahar, 1976.

WINNICOTT, D. W. Natureza humana. Rio de Janeiro: Imago, 1990.

WINNICOTT, D. W. O brincar e a realidade. Rio de Janeiro: Imago, 1975.

Texto recebido em 20 jul. 2003

Texto aprovado em 14 set. 2003 